\title{
Studi Laboratorium Pengaruh Nanocomposite Nanosilika dan Arang Cangkang Kelapa Sawit Dengan Variasi Temperatur Pemanasan Terhadap Free Water dan Kekuatan Semen Pemboran
}

\author{
Novrianti \\ Program Studi Teknik Perminyakan Universitas Islam Riau
}

\begin{abstract}
Abstrak
Semen merupakan salah satu parameter penting dalam proses pemboran. Parameter keberhasilan penyemenan sumur migas antara lain adalah apabila nilai free water, compressive strength (CS) dan shear bond strength (SBS) telah sesuai dengan standar penyemenan American Petroleum Association (API). Menurut API Nilai Free water maksimal adalah $3.5 \mathrm{ml}$, nilai Compressive strength minimum yang direkomendasikan oleh API untuk dapat melanjutkan operasi pemboran adalah 500 Psi sedangkan shear bond strength lebih dari 100 psi. Beberapa additive telah dipergunakan untuk meningkatkan kekuatan semen. Studi ini dilakukan untuk mengetahui pengaruh nanocomposite antara additive nano silika dan arang cangkang kelapa sawit yang dipanaskan dengan variasi temperature terhadap nilai free water, compressive strength (CS) dan shear bond strength (SBS) semen pemboran.

Eksperimen ini menggunakan konsentrasi arang cangkang kelapa sawit dengan variasi temperature pemanasan $400^{\circ} \mathrm{C}$, $500^{\circ} \mathrm{C}, 600^{\circ} \mathrm{C}, 700^{\circ} \mathrm{C}, 800^{\circ} \mathrm{C}$ dan $900^{\circ} \mathrm{C}$ sebesar $3 \%$ by weight on cement dengan tambahan nano silika sebesar $0,019 \%$. Setelah suspense semen selesai dibuat, free water ditentukan dengan menggunakan gelas ukur yang diisi oleh suspensi semen sebanyak $250 \mathrm{ml}$. Mendiamkan selama 2 jam sehingga terjadi air bebas pada bagian atas gelas ukur. Sedangkan untuk compressive strength (CS) dan shear bond strength (SBS) suspense semen dituangkan kedalam cetakan dan dikeringkan selama 24 jam dan setelah kering maka sampel akan diuji pembebanan dengan menggunakan alat hydraulic Press. Uji pembebanan ini dilakukan sampai sample pecah. Tekanan pada saat sample pecah dicatat sebagai data pembebanan maksimum untuk menentukan compressive strength (CS) dan shear bond strength (SBS).

Hasil penelitian menunjukkan bahwa nilai free water, compressive strenght dan shear bond strenght maksimum diperoleh pada saat arang cangkang kelapa sawit dipanaskan pada temperature $700^{\circ} \mathrm{C}$. Nilai free water yang diperoleh adalah $3.2 \mathrm{ml}$, compressive strength yang diperoleh adalah 1433.01 Psi dan shearbond strength 163.45 Psi.
\end{abstract}

Kata Kunci: Free Water, Compressive Strenght, Shear Bond Strenght, Nanocomposite, Cangkang Kelapa Sawit

\begin{abstract}
Cement is one of the important parameter in the drilling process. The success of cementing oil and gas wells, among others, if the value of free water, compressive strength (CS) and shear bond strength (SBS) complies with the standards cementing American Petroleum Association (API). The recommended maximum free water by API is $3.5 \mathrm{ml}$, minimum compressive strength to conduct cementing process is $500 \mathrm{Psi}$, and the shear bond strength is greater than $100 \mathrm{Psi}$. Some additives were used to increase the strength of cement. This study was conducted to determine the effect of nano-composite among nanosilica additive and palm-shell charcoal that heated by variety heating temperature to free water, compressive strength and shear bond strength value of drilling cement.

This experiment using palm-shell charcoal concentration with variety of heating temperature; $400^{\circ} \mathrm{C}, 500^{\circ} \mathrm{C}, 600^{\circ} \mathrm{C}, 700^{\circ} \mathrm{C}$, $800^{\circ} \mathrm{C}$, and $900^{\circ} \mathrm{C}$ in the amount of $3 \%$ by weight on cement with addition nano-silica in the amount of $0.019 \%$. After the cement suspension is complete, free water is determined using the measuring cup filled with cement suspension of $250 \mathrm{ml}$. Silence for 2 hours resulting in the free water at the top of the measuring cup. As for compressive strength (CS) and shear bond strength (SBS), the suspension is poured to the mold and be dried for 24 hours. Then, the sample was ready to use for the experiment using hydraulic press. The load test was conducted till the sample is cracked. The pressure when the sample was crashed as the maximum load data to determine compressive strength (CS) and shear bond strength (SBS).

The result showed the maximum of free water, the maximum compressive strength and shear bond strength values was obtained when the palm-shell charcoal was heated at temperature $700^{\circ} \mathrm{C}$. The result for free water is $3.2 \mathrm{ml}$, compressive strength is 1433.01 Psi and shear bond strength 163.45 Psi.
\end{abstract}

Keywords: Free Water, Compressive Strenght, Shear Bond Strenght, Nanocomposite, Palm Shell Carbon

Corresponding Author e-mail address: novrianti@eng.uir.ac.id 


\section{PENDAHULUAN}

Pada umumnya operasi penyemenan bertujuan untuk melekatkan casing pada dinding lubang sumur, melindungi casing dari masalah-masalah mekanis sewaktu operasi pemboran berlangsung (seperti getaran), melindungi casing dari fluida formasi yang bersifat korosi dan untuk sebagai pemisah antar lapisan formasi di belakang casing (Burgoyne, 1986).

Agar dapat menyokong casing dan rangkaian peralatan yang berada di permukaan lainnya serta menahan tekanan formasi maka nilai free water, compressive strength dan shear bond strength semen yang dihasilkan pada proses penyemenan harus sesuai dengan standard API. Apabila harga free water ini terlalu besar melebihi batas air maksimum maka akan terjadi pori-pori pada semen. Ini akan mengakibatkan semen mempunyai permeabilitas besar sehingga dapat menyebabkan kontak fluida antara formasi dengan annulus dan strength semen berkurang. Compressive strength minimum yang direkomendasikan oleh API untuk dapat melanjutkan operasi pemboran adalah 500 Psi sedangkan shear bond strength lebih dari 100 psi. Compressive strength didefinisikan sebagai kekuatan semen dalam menahan tekanan yang berasal dari formasi dan casing atau menahan tekanan pada arah horizontal sedangkan shear bond strength didefinisikan sebagai kekuatan semen dalam menahan berat casing atau menahan tekanan pada arah vertikal.

Dalam beberapa tahun terakhir upaya-upaya besar telah dilakukan untuk meningkatkan kekuatan semen pemboran dengan tambahan material yang bersifat pozzolanik (additive) pada semen bersama sama dengan tambahan bahan kimiawi pada campuran bubur semen. Salah satu upaya yang dilakukan adalah melakukan penelitian dan percobaan menggunakan partikel nanosilica (SiO2), Oksida besi $\left(\mathrm{Fe}_{2} \mathrm{O}_{3}\right)$, dan aluminium oksida $\left(\mathrm{Al}_{2} \mathrm{O}_{3}\right)$ telah banyak digunakan untuk meningkatkan strength dan mengurangi filtration loss pada saat operasi penyemenan.(V. Ershadi, 2011). Menurut ASTM C618-93 bahan additive yang mempunyai komposisi kimia silica oksida $\left(\mathrm{SiO}_{2}\right)$, Oksida besi $\left(\mathrm{Fe}_{2} \mathrm{O}_{3}\right)$, dan aluminium oksida $\left(\mathrm{Al}_{2} \mathrm{O}_{3}\right)$ lebih tinggi dari $70 \%$ dapat dimanfaatkan sebagai bahan additive. Pozzolan yang terbentuk dari material seperti aluminium dan silika yang bereaksi dengan kalsium hidroksida $(\mathrm{CaOH})$ dapat membentuk masa padat dengan ikatan yang keras dan tidak dapat larut di dalam air.

Indonesia sebagai negara yang beriklim tropis merupakan negara penghasil kelapa sawit terbesar kedua di dunia. Cangkang kelapa sawit memiliki kadar silika sekitar 92\% (Nurhayati et al., 2005). Hal ini mengindikasikan bahwa cangkang kelapa sawit dapat menjadi material pozzolanik. Material pozzolan dapat bereaksi dan menambah compressive strength semen (Nelsson, 1990). Sysca (2015) melakukan penelitian dengan menggunakan karbon cangkang kelapa sawit untuk menentukan kekuatan semen dan menyimpulkan bahwa persentase yang optimum dalam meningkatkan kekuatan semen yaitu 3\% by weight on cement.

Penelitian dari Patcharin Worathanakul et al. (2009) menyimpulkan bahwa kadar silika dapat ditingkatkan dengan proses pemanasan. Menurut Hawley (1999) proses pemurnian arang terjadi pada temperature $500{ }^{\circ} \mathrm{C}$. Kadar karbon meningkat mencapai $90 \%$. Namun pemanasan diatas temperatur $700^{\circ} \mathrm{C}$, hanya menghasilkan gas hidrogen.

Nanosilika (nano-SiO2) adalah silika yang sangat halus dan telah digunakan sebagai campuran semen baik di ladang minyak maupun dalam industri konstruksi dan teknik sipil. Karena sifatnya sangat halus dan material pozzolanik reaktivitas tinggi, nanosilika telah digunakan untuk meningkatkan 
impermeabilitas suspensi dan sifat mekanik material mengeras. Dengan partikel silika yang sangat halus dalam semen matriks, porositas dan permeabilitas secara signifikan menurun dan compressive strength meningkat, tentunya dengan penambahan nanosilika yang tepat kedalam suspensi semen.

Nanosilika merupakan material pozzolanik yang sangat efektif, karena terdiri dari partikel-partikel yang sangat halus, sekitar 1000 kali lebih kecil dari rata-rata partikel semen, hal ini memungkinkan nanosilika dapat menjadi additive yang sangat baik untuk meningkatkan kekuatan dan daya tahan semen. Penelitian ini dilakukan dengan menggabungkan additive nanosilika dan arang cangkang kelapa sawit yang dipanaskan pada temperature berbeda - beda untuk menentukan pengaruh nanosilika dan arang cangkang kelapa sawit terhadap nilai maksimum compressive strength dan shear bond strength semen pemboran.

\section{METODE PENELITIAN}

Persiapan peralatan dan bahan pengujian merupakan proses awal yang dilakukan sebelum penelitian dimulai, dilanjutkan dengan pengujian basic cement slurry sesuai standard American Petroleum Institute, lalu menguji pengaruh penambahan gabungan antara nanosilika dengan additive cangkang kelapa sawit yang dipanaskan dengan temperatur pemanasan berbeda - beda terhadap strength semen pemboran.

Bahan utama yang disiapkan sebelum melakukan penelitian adalah semen pemboran dengan klasifikasi API kelas G produksi PT. Holcim, nanosilika dan cangkang kelapa sawit sebagai additive. Nanosilika (nano-SiO2) yang digunakan dalam penelitian ini sebesar $0.019 \%$ yang memiliki karakteristik seperti terlihat pada tabel 1 .

Karbon cangkang kelapa sawit yang digunakan merupakan karbon cangkang kelapa sawit produksi CV. Berkat Jaya dari wilayah Sampit - Kalimantan Tengah sebanyak 3 kilo gram. Karbon cangkang kelapa sawit yang telah ada kemudian dihaluskan menggunakan blender dan disaring menggunakan sieve analysis dengan ukuran 200 mesh. Sieve analysis yang digunakan adalah alat yang terdapat di Laboratorium Teknik Perminyakan Universitas Islam Riau. Komposisi kimia yang terdapat pada karbon cangkang sawit dapat dilhat pada table 2 .

Tabel 1. Karakteristik $\mathrm{Nano}-\mathrm{SiO}_{2}$

\begin{tabular}{lc}
\hline Densitas & $2.17-2.66 \mathrm{gr} / \mathrm{cm}^{3}$ \\
\hline Melting point & $\pm 1700^{\circ} \mathrm{C}$ \\
\hline Boiling point & $2230^{\circ} \mathrm{C}$ \\
\hline Warna & Putih \\
\hline Ukuran Partikel & $10-20$ nanometer \\
\hline Bulk Density & $0.011 \mathrm{gr} / \mathrm{ml}$ \\
\hline
\end{tabular}

Tabel 2. Komposisi Kimia Karbon Cangkang Kelapa Sawit

\begin{tabular}{lc}
\hline Senyawa Kimia & Persentase $(\boldsymbol{\%})$ \\
\hline $\mathrm{MgO}$ & 4.9 \\
\hline $\mathrm{Al}_{2} \mathrm{O}_{3}$ & 2.2 \\
\hline $\mathrm{SiO}_{2}$ & 30.1 \\
\hline $\mathrm{P}_{2} \mathrm{O}_{5}$ & 19.6 \\
\hline
\end{tabular}




\begin{tabular}{ll}
\hline $\mathrm{SO}_{3}$ & 3.28 \\
\hline $\mathrm{K}_{2} \mathrm{O}$ & 17.5 \\
\hline $\mathrm{CaO}$ & 14.6 \\
\hline $\mathrm{Fe}_{2} \mathrm{O}_{3}$ & 5.08 \\
\hline $\mathrm{CuO}$ & 0.388 \\
\hline $\mathrm{ZnO}$ & 2.30
\end{tabular}

Cangkang kelapa sawit yang sudah disaring dipanaskan pada temperatur pemanasan yang berbeda beda yaitu $400^{\circ} \mathrm{C}, 500^{\circ} \mathrm{C}, 600^{\circ} \mathrm{C}, 700^{\circ} \mathrm{C}, 800^{\circ} \mathrm{C}$ dan $900^{\circ} \mathrm{C}$ dengan menggunakan oven furnace. Pembuatan suspense semen dilakukan dengan cara mencampurkan semen, air, bentonie, Cacl2, 0,019\% nanosilica dan $3 \%$ by weight on cement karbon cangkang kelapa sawit dengan temperatur pemanasan yang berbeda - beda yaitu $500^{\circ} \mathrm{C}, 600^{\circ} \mathrm{C}, 700^{\circ} \mathrm{C}, 800^{\circ} \mathrm{C}$ dan $900^{\circ} \mathrm{C}$. Suspense semen dibuat dengan cara memasukkan air terlebih dahulu ke dalam cement mixer. Menyalakan mixer dengan kecepatan rendah $(4000 \pm 200 \mathrm{rpm})$ lalu memasukkan semen, additive dan cangkang kelapa sawit, melanjutkan pengadukan dengan kecepatan tinggi $(1200 \pm 500 \mathrm{rpm})$ selama 10-15 menit. Terdapat 6 sample yang digunakan dalam penelitian ini seperti yang terdapat pada tabel 3 .

Pengujian free water suspensi semen menggunakan gelas ukur, kemudian mengisi gelas ukur tersebut dengan suspensi semen sebanyak $250 \mathrm{ml}$. Mendiamkan selama 2 jam sehingga terjadi air bebas pada bagian atas gelas ukur. Setelah 2 jam catat berapa volume air bebas yang dihasilkan sebagai freewater. Untuk pengujian compressive strength dan shearbond strength suspense dituangkan kedalam cetakan cetakan kubik dan cetakan silider yang kemudian akan digunakan untuk pengujian compressive strength dan shearbond strength. Tutup cetakan sampel dengan aluminium foil dan kemudian dengan plastik hingga rapat lalu rendam dalam water bath temperature controller pada temperatur $140^{\circ} \mathrm{F}$. Diamkan selama 24 jam, setelah 24 jam sampel diangkat dari water bath temperature controller kemudian buka sampel dari cetakan kubik dan silinder. Selanjutnya akan diuji pembebanan dengan menggunakan alat hydraulic press. Uji pembebanan ini dilakukan sampai sample pecah. Tekanan pada saat sample pecah itu dicatat sebagai data pembebanan maksimum untuk menentukan compressive strength dan shear bond strength.

Tabel 3. Komposisi Sampel Semen

\begin{tabular}{lc}
\hline Nama Sample & Temperatur Pemanasan $\left({ }^{\circ} \mathrm{C}\right)$ \\
\hline S1 & SD $+0,019 \%$ Nano-SiO2 + Cangkang Kelapa Sawit $400^{\circ} \mathrm{C}$ \\
\hline S2 & SD $+0,019 \%$ Nano-SiO2 + Cangkang Kelapa Sawit $500^{\circ} \mathrm{C}$ \\
\hline S3 & SD + 0,019\% Nano-SiO2 + Cangkang Kelapa Sawit $600^{\circ} \mathrm{C}$ \\
\hline S4 & SD $+0,019 \%$ Nano-SiO2 + Cangkang Kelapa Sawit $700^{\circ} \mathrm{C}$ \\
\hline S5 & $\mathrm{SD}+0,019 \%$ Nano-SiO2 + Cangkang Kelapa Sawit $800^{\circ} \mathrm{C}$ \\
\hline S6 & $\mathrm{SD}+0,019 \%$ Nano-SiO2 + Cangkang Kelapa Sawit $800^{\circ} \mathrm{C}$ \\
\hline
\end{tabular}

\section{HASIL DAN PEMBAHASAN}

Pengaruh campuran $0,019 \%$ nanosilica dengan cangkang kelapa sawit temperatur pemanasan $500^{\circ} \mathrm{C}$, $600^{\circ} \mathrm{C}, 700^{\circ} \mathrm{C}, 800^{\circ} \mathrm{C}$ dan $900^{\circ} \mathrm{C}$ terhadap free water dapat dilihat pada Gambar 1. 


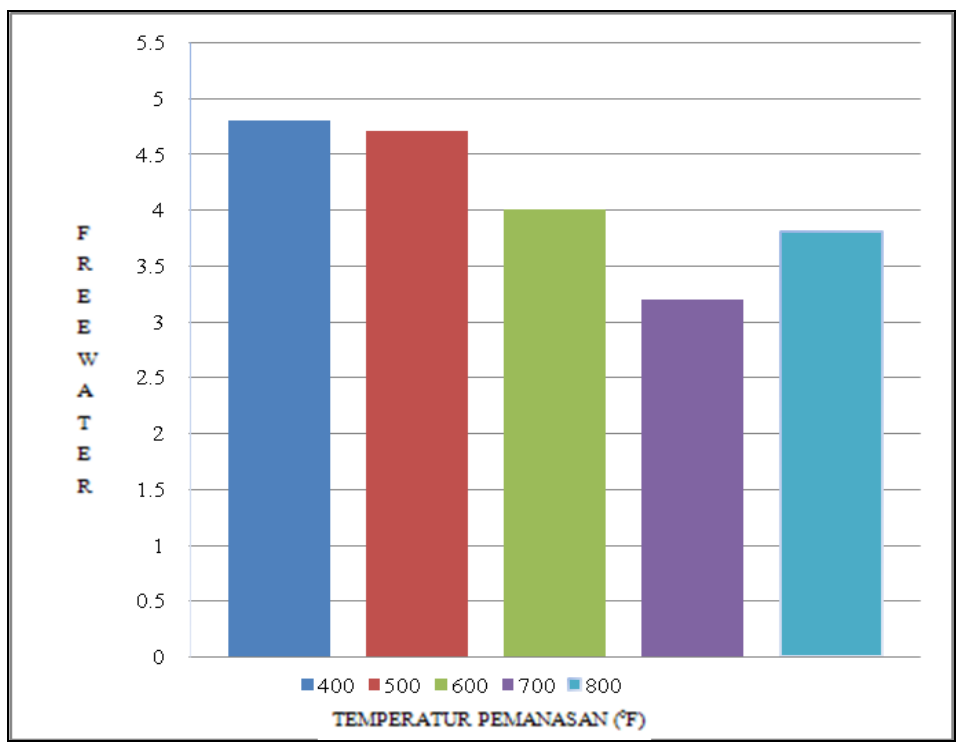

Gambar 1. Free Water

Berdasarkan gambar 1 terlihat bahwa nilai free water yang sesuai dengan American Petroleum Association (API) adalah sampel 4 yang merupakan campuran antara 0,019\% nanosilika dengan cangkang kelapa sawit temperature $700^{\circ} \mathrm{C}$. Nilai Free Water untuk arang cangkang sawit dengan temperature pemanasan $700^{\circ} \mathrm{C}$ adalah $3.2 \mathrm{ml}$.

Gambar 2 menunjukkan pengaruh campuran 0,019\% nanosilika dengan cangkang kelapa sawit temperature pemanasan $500^{\circ} \mathrm{C}, 600^{\circ} \mathrm{C}, 700^{\circ} \mathrm{C}, 800^{\circ} \mathrm{C}$ dan $900^{\circ} \mathrm{C}$ terhadap nilai compressive strenght

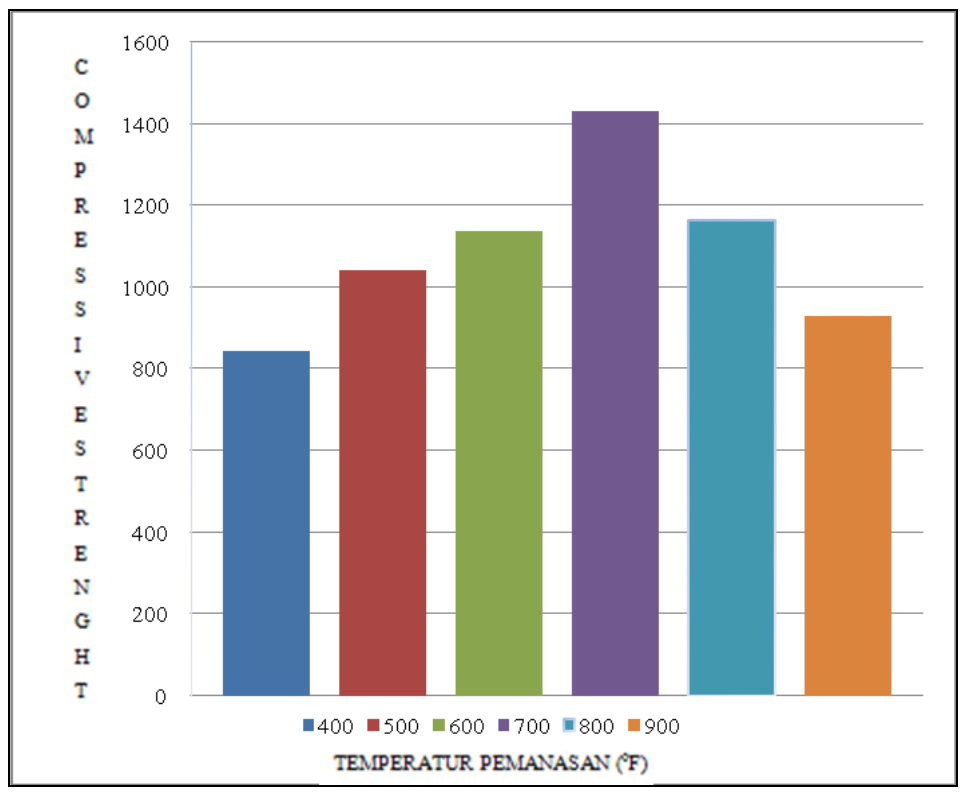

Gambar 2. Compressive Strenght

Gambar di atas menunjukkan adanya peningkatan compressive strength semen dengan menambahkan nano silika dan additive cangkang kelapa sawit dengan variasi temperatur pemanasan cangkang kelapa sawit. Semen yang ditambahkan nanosilika dan additive cangkang kelapa sawit dengan temperatur $400^{\circ} \mathrm{C}$ sampai $700^{\circ} \mathrm{C}$ mengalami peningkatan strength semen setiap kenaikan temperatur pemanasan. 
Nilai compressive strength pada $400^{\circ} \mathrm{C}$ sebesar $844,12 \mathrm{Psi}$, compressive strength pada $500^{\circ} \mathrm{C}$ sebesar 1041,3 Psi, compressive strength pada $600^{\circ} \mathrm{C}$ sebesar 1139,01 Psi dan compressive strength pada $700^{\circ} \mathrm{C}$ sebesar 1433,01 Psi. Pada temperatur pemanasan $800^{\circ} \mathrm{C}$ dan $900^{\circ} \mathrm{C}$, terjadi penurunan nilai compressive strength semen pemboran. Nilai compressive strength pada $800^{\circ} \mathrm{C}$ sebesar 1165.71 Psi dan compressive strength pada $900^{\circ} \mathrm{C}$ sebesar 930,11 Psi.

Additive cangkang kelapa sawit yang dipanaskan dengan temperatur pemanasan $500^{\circ} \mathrm{C}$, mengalami proses pembentukan arang murni, sehingga kadar karbon aktif yang ada di dalam arang cangkang kelapa sawit meningkat $90 \%$. Meningkatnya karbon aktif yang ada dalam cangkang kelapa sawit, menyebabkan daya ikat karbon terhadap semen semakin besar dan meningkatkan nilai strength semen. Tetapi setelah melewati temperatur optimum pemanasan arang cangkang kelapa sawit nilai compressive strength semen mengalami penurunan, karena temperatur pemanasan di atas $700^{\circ} \mathrm{C}$ kandungan karbon aktif yang ada di dalam cangkang kelapa sawit mulai berkurang karena adanya gas hydrogen.

Gambar 3 menunjukkan pengaruh campuran 0,019\% nanosilika dengan cangkang kelapa sawit temperature pemanasan $500^{\circ} \mathrm{C}, 600^{\circ} \mathrm{C}, 700^{\circ} \mathrm{C}, 800^{\circ} \mathrm{C}$ dan $900^{\circ} \mathrm{C}$ terhadap nilai shear bond strenght .

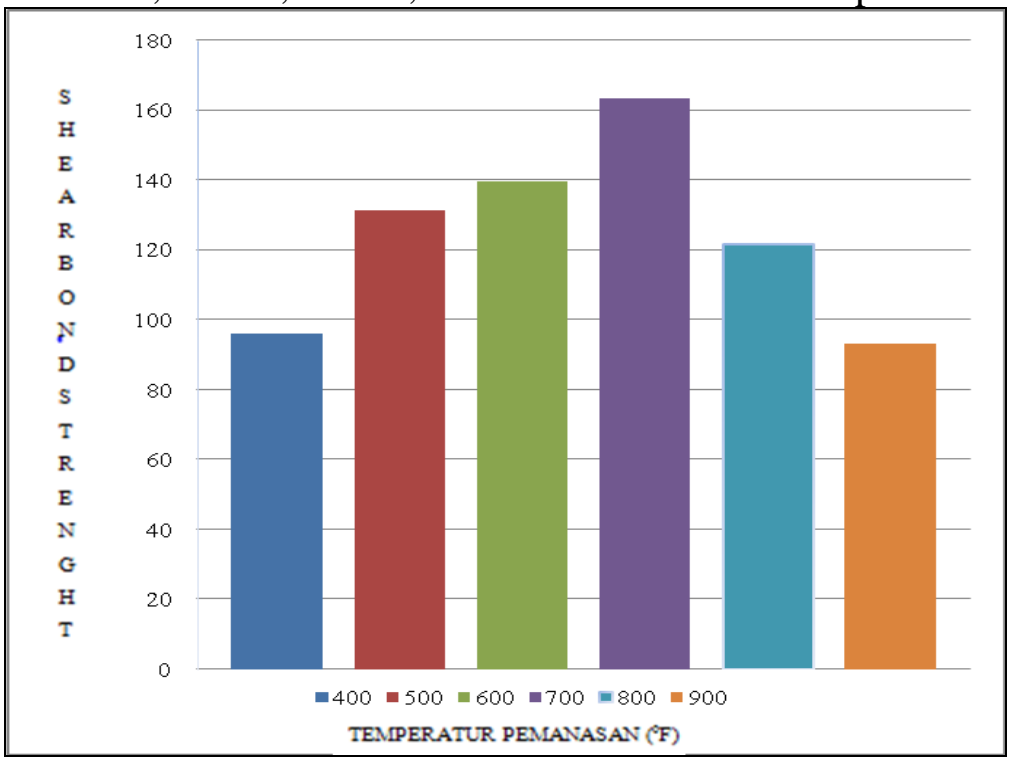

Gambar 3. Shear Bond Strenght

Gambar 3 menunjukkan adanya pengaruh nano silika dan cangkang kelapa sawit terhadap peningkatan shear bond strength semen pemboran. Semen yang ditambahkan additif cangkang kelapa sawit dan $0,019 \%$ nano silika dengan temperatur $400^{\circ} \mathrm{C}-700^{\circ} \mathrm{C}$ mengalami peningkatan shear bond strength sedangkan pada temperatur pemanasan $800^{\circ} \mathrm{C}$ dan $900^{\circ} \mathrm{C}$, terjadi penurunan nilai strength semen. Hal ini menunjukkan bahwa temperature pemanasan $700^{\circ} \mathrm{C}$ merupakan temperature optimum untuk meningkatkan nilai shear bond strength. Nilai shear bond strength pada temperatur pemanasan cangkang kelapa sawit $400^{\circ} \mathrm{C}$ adalah 96,28 Psi, Nilai shear bond strength pada tempearur pemanasan $500^{\circ} \mathrm{C}$ adalah $131,35 \mathrm{Psi}$, Nilai shear bond strength pada tempearur pemanasan $600^{\circ} \mathrm{C}$ adalah 139,74 Psi, Nilai shear bond strength pada tempearur pemanasan $700^{\circ} \mathrm{C}$ adalah 163,45 Psi. Nilai shear bond strength pada temperature pemanasan $800^{\circ} \mathrm{C}$ dan $900^{\circ} \mathrm{C}$ mengalami penurunan dimana nilai shear bond strength pada temperature pemanasan adalah 121,81 Psi dan shear bond strength pada temperature pemanasan $900^{\circ} \mathrm{C}$ adalah 93,23 Psi. 


\section{KESIMPULAN}

1. Nilai free water optimum yang diperoleh dengan penambahan additive 0,019\% nanosilika dan cangkang kelapa sawit dengan variasi temperature pemanasan adalah $3.2 \mathrm{ml}$ pada temperatur $700^{\circ}$.

2. Nilai compressive strength optimum yang diperoleh dengan penambahan additive 0,019\% nanosilika dan cangkang kelapa sawit dengan variasi temperature pemanasan adalah 1433,01 Psi pada temperatur $700^{\circ}$.

3. Nilai shear bond strength optimum yang diperoleh dengan menambahkan additive 0,019\% nanosilika dan cangkang kelapa sawit dengan variasi temperature pemanasan adalah sebesar sebesar 163,45 Psi pada temperature $700^{\circ} \mathrm{C}$

\section{DAFTAR PUSTAKA}

American Petroleum Institute. (2002). API Specification 10A. Specification for well cements and

Materials for Well Cementing Twenty-Third Edition. Washington, D.C., USA.

Buntoro, Aris and Rubiandini, Rudi. (2001). The Effect Of Neat Magnesium Oxide (MgO) As Expanding Additive With Burning Temperature $1200{ }^{\circ} \mathrm{C}$ And $1300^{\circ} \mathrm{C}$ On Cement Shear Bond Strength At High Pressure And Temperature. Proceeding of The 5thInaga Annual Scientific Conference And Exhibition. Yogyakarta

Burgoyne, Adam T. Jr. (1986). Applied Drilling Engineering. SPE, USA, 1986. 85-103

Ershadi, V., et al. "The effect of nanosilica on cement matrix permeability in oil well to decrease the pollution of receptive environment." Int. J. Environ. Sci. Develop 2 (2011): 128-132.

Hawley. (1999). The effect of heating on the manufracture of activated charcoal.

Nelson, E. B. (Ed.). (1990). Well cementing. Newnes.

Nurhayati, Tjutju., Desviana and Sofyan, Kurnia. (2005). Oil-Palm Shell as the Alternative Raw Material for the Integrated Production of Charcoal with Pyroligneous Acid / Liquid.

Pranadipa, Imam. (2010). Utilization of Oil Palm Shell Charcoal As An Extender In Oil Well Cement : 34th Annual Convention And Exhibition, Indonesian Petroleum Association.

Ali, Sysca Putri. (2015). Studi Laboratorium penggunaan additive komposit nanosilika dan cangkang kelapa sawit untuk meningkatkan strength semen pemboran. Tugas Akhir. Universitas Islam Riau.

Siregar, Efrando. (2012). Studi Pemanfaatan Limbah Abu Sekam Padi Dan Arang Cangkang Kelapa Sawit Sebagai Light Weight Additive Untuk Meningkatkan Strength Semen Pemboran. Universitas Islam Riau, Pekanbaru.

Subiyanto, Bambang., Basri, Hasan., Sari, Linda N., Triastuti, Rosalita, Yetvi. (2007). Komponen Kimia Cangkang Kelapa Sawit (Elaeis Guineensis). LIPI, Cibinong.

Worathanakul, Patcharin., Payubnop, Wisaroot and Muangpet, Akhapon. (2009). Characterization for Post-treatment Effect of Bagasse Ash for Silica Extraction. World Academy of Science, Engineering and Technology. 